\title{
REVIEW
}

\section{APPROACHES TO UNDERSTANDING THE PHENOMENON OF MISSED/RATIONED/UNFINISHED CARE - A LITERATURE REVIEW}

\author{
Dominika Kalánková, Katarína Žiaková, Radka Kurucová \\ Department of Nursing, Jessenius Faculty of Medicine in Martin, Comenius University in Bratislava, Slovakia
}

Received April 27, 2018; Accepted October 15, 2018. Copyright: This is an open access article distributed under the terms of the Creative Commons Attribution International License (CC BY). http://creativecommons.org/licenses/by/4.0/

\begin{abstract}
Aim: This literature review aims to describe, analyze and compare approaches to the phenomenon of missed/rationed/unfinished nursing care, in order to better our understanding of it. Design: A narrative literature review. Methods: A method of content analysis of studies published in the scientific databases PubMed, ScienceDirect, ProQuest, and Wiley Library Online was used. Studies were selected using a set of criteria and keywords for the period 2000-2018. Twentyone studies were analyzed in the processing of the literature review. Results: We identified the four most common approaches or conceptual frameworks used to describe the phenomenon from the available literature - Missed Care, Implicit Rationing of Nursing Care, Task Undone and the theoretical proposition, Failure to Maintain, each of which explicitly describes a particular aspect of the phenomenon, and provides us with a theoretical framework and structure. Conclusion: This review contributes to the overview of particular approaches or theoretical frameworks used to understand the phenomenon. It is necessary to understand the terminology, and to use it appropriately. All approaches identified associations between the phenomenon and negative outcomes for patients as a quality-of-care indicator.
\end{abstract}

Keywords: approach, conceptual framework, missed care, rationing care, unfinished care, failure to maintain.

\section{Introduction}

Nurses represent the first line of care provided to patients. They are the most numerous group of healthcare professionals, providing care based on the bio-psycho-social and spiritual needs of patients. Nurses also fulfill the roles of coordinators, providers, and evaluators of nursing care (Jones, Hamilton, Murry, 2015). In the last decade, an increasing amount of literature has been concerned with the phenomenon of implicit rationing of nursing care. The phenomena exists in healthcare when the need for services exceeds the available resources while providing care. Rationing of care includes decisions to withhold beneficial services due to insufficient resources. According to Jones et al. (2016), the prevalence of rationing by nurses of one or more nursing activities is between $55 \%$ and $98 \%$.

There is a body of literature refering to the following terms: nursing care left undone (Aiken et al., 2001) missed care (Kalisch, 2006), unfinished care (Sochalski, 2004), rationing of nursing care (Schubert

Corresponding author: Dominika Kalánková, Department of Nursing, Jessenius Faculty of Medicine in Martin, Comenius University in Bratislava, Malá Hora 5, Martin, Slovakia; e-mail: kalankoval@uniba.sk et al., 2007), unmet nursing care needs (Lucero, Lake, Aiken, 2009), task incompletion (Al-Kandari, Thomas, 2009), nursing care left incomplete (Aiken et al., 2013) care left undone (Ausserhofer et al., 2014), work left undone (Leary, White, Yarnell, 2014), nursing tasks left undone (Bekker et al., 2015), or failure to maintain (Bail, Grealish, 2016). The number of studies is increasing rapidly, and its content suggests that this phenomenon is a global problem obscured by inconsistency in terminology (Jones, 2015; Zeleníková et al., 2017). These terms can be found in different types of studies. Most of them are published in English as quantitative studies (Ball et al., 2014; Lake, Germack, Viscardi, 2016) and reported under multiple labels (missed nursing care, unfinished nursing care, omitted nursing care, implicitly rationed care, care left undone, care rationing, failure to maintain, and others). It is challenging to choose a single English term acceptable to all healthcare professionals (especially nurses) that adequately describes the phenomenon. Even more problematic is the translation of this term into different languages in order for it to be understood by the whole nursing community (Zeleníková et al., 2017).

One way forward is to seek conceptual clarification of the phenomenon. According to Jones, Hamilton, 
Murry (2015), there are several approaches to understanding unfinished care: the missed care approach, the implicit rationing approach, and the task undone approach. These approaches use different conceptual definitions, and for each of them a specific measuring tool has been developed. Several conceptual analyses and frameworks have already been published on missed/rationed/unfinished nursing care (Schubert et al., 2007; Kalisch, Landstrom, Hinshaw, 2009; Lucero, Lake, Aiken, 2009; Hessels et al., 2015; Bail, Grealish, 2016; Bassi et al., 2018).

\section{Aim}

This literature review aims to describe, analyze and compare approaches to the phenomenon of missed/rationed/unfinished nursing care, and the phenomenon of failure to maintain, in order to better our understanding of them.

\section{Methods}

\section{Design}

A narrative literature review.

\section{Eligibility criteria}

Papers were selected according to the following search criteria: in English, published between 20002018, full-text available, and qualitative and quantitative studies. After application of the search criteria, the retrieved articles were evaluated for relevant studies meeting the inclusion criteria. Articles were eligible for inclusion if they contained: a) a conceptual framework, theory or approach related to missed care, implicit rationing of nursing care and unfinished care; b) were reports of quatitative research associated with development of a conceptual definition, framework, clarification of concepts regarding missed, ration, and unfinished nursing care; c) were reports of quantitative research related to the use of instruments regarding the particular approaches or frameworks; d) were original reports related to the development of the specific instruments to measure missed, implicit rationing of, or unfinished nursing care, or related to the evaluation of psychometric characteristics of the selected instruments.

\section{Sources}

Four scientific databases were used to obtain relevant sources dealing with the specific issue (PubMed, ScienceDirect, ProQuest, and Wiley Library Online).

\section{Search}

The search was conducted between December 2017 and February 2018 using the keywords missed care unfinished care - rationing care - conceptual framework - approach. To combine the keywords, Boolean operators "AND" and "OR" were applied in the search. The same criteria for each scientific database were applied.

\section{Study selection}

The search produced 1,849 records. The initial screening of titles to exclude irrelevant studies, was carried out by two independent researchers, resulting in 187 abstracts screened. After removing duplicates, 156 studies were included in the review process. A narrative literature review then proceeded (see Figure 1), according to PRISMA recommendations.

\section{Data analysis}

Only studies dealing with the four specific conceptual frameworks and approaches were analyzed and involved in the outline to meet the aim of the review. Following application of PRISMA, 21 studies (Table 1) were included in the review process, concerning the following topics:

- missed care approach; $n=6$

- implicit rationing of nursing care approach; $\mathrm{n}=8$

- task undone approach; $\mathrm{n}=5$

- failure to maintain; $\mathrm{n}=2$.

\section{Results}

\section{The missed care approach}

Kalisch (2006) first identified the phenomenon of missed nursing care in her qualitative study identifying regularly missed nursing activities in medical, surgical, and intensive care units (ICU). The research not only identified regular rates of occurrence, but also the underlying reasons for the overt occurrence of this situation. Kalisch recognized nine essential elements of missed nursing care, and their underlying reasons. The essential elements included postoperative care and ambulation, turning positions, delayed or missed feedings, patient education, discharge arrangement, emotional care, hygiene, intake and output documentation, and observation. The underlying reasons comprised inadequate staffing, poor use of existing staff resources, nursing intervention time management, poor teamwork, ineffective delegation, existing habits, and denial (Kalisch, Landstrom, Hinshaw, 2009; Kalisch et al., 2011). The research was conducted in two acute care hospitals in the USA, and analyzed 25 focus groups consisting of nurses, 


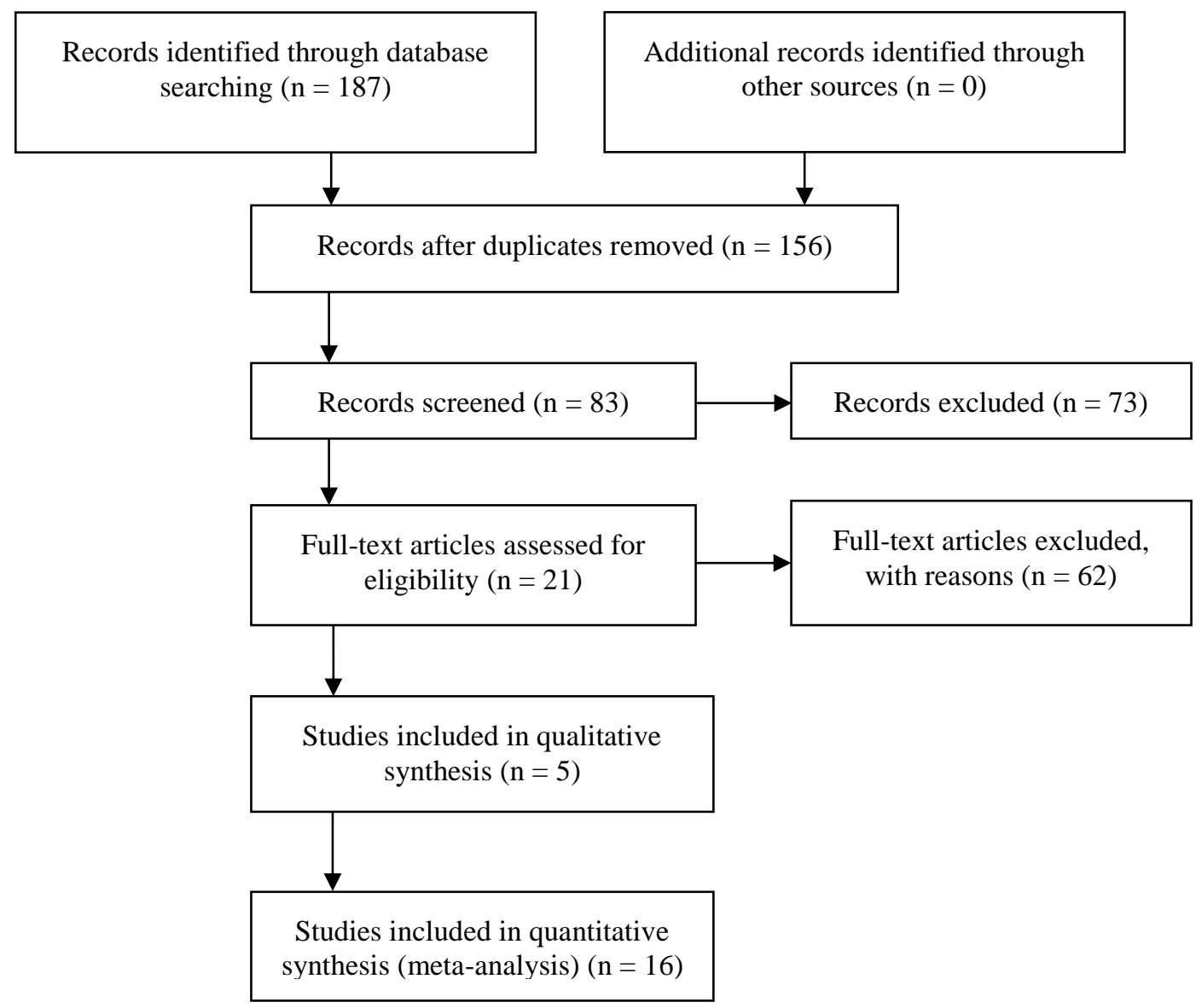

Figure 1 Flow chart - PRISMA recommendations

nursing assistants, and unit secretaries. The study exposed numerous factors, supplying key data about missed care. The findings acknowledged that additional analysis of missed nursing care is required due to the ambiguityof the widely used definition, and its difference to other related concepts (Kalisch, 2006; Kalisch, Landstrom, Hinshaw, 2009). Kalisch, Landstrom, Hinshaw (2009) describes the phenomenon of missed nursing care as "any aspect of required patient care that is omitted (either in part or whole), or delayed".

The Missed Nursing Care Model exemplifies categories described by nurses in acute care settings that contribute to missed care: a) external antecedents of missed nursing care; b) elements of the nursing process; c) internal processes of nurses, and d) patient outcomes. The model also identifies external factors present within the setting of the care environment (Kalisch, Landstrom, Hinshaw, 2009). External factors of missed nursing care include the care demands on labor resources (the number and type of nurses and healthcare assistants, depending on demands of care - skills, level of education, experience); material resources (availability of medication, medical supplies and standard nursing care equipment); and the communication and relationship aspect (the quality of communication between nurses and doctors, as well as between the nursing staff and secondary personnel - cooperation). Nurses and nursing staff should consider the type of care deemed necessary when any of these external factors are present. When labor or material resources are inadequate, nurses should prioritize how to make best use of existing materials and resources (Kalisch, 2006; Kalisch, Landstrom, Hinshaw, 2009). These external factors interact closely with each aspect of the nursing process and are filtered by four internal processes in nursing staff: normative team behaviors (norms of the team within the staff); the prioritization process (the prioritization of the care requirements); personal values, attitudes and beliefs (the roles and obligations of nurses); and characteristic behavior. All these factors and influences result in incidences of missed nursing care.

Kalisch and Lee (2010) argue that missed nursing care is the result of nurse decision-making in response to the external environment. However, it is important to recognize that actions provoke various 
Table 1 Overview of studies related to the concept of missed/rationed/unfinished care phenomenon (Part 1)

\begin{tabular}{|c|c|c|c|c|c|}
\hline Primary focus & Source & Objective & Design & Sampling & Main findings \\
\hline \multirow{2}{*}{$\begin{array}{l}\text { Missed care } \\
\text { approach }\end{array}$} & $\begin{array}{l}\text { Kalisch, Lee } \\
(2010)\end{array}$ & $\begin{array}{l}\text { To explore the impact of teamwork on } \\
\text { the extent and nature of missed nursing } \\
\text { care. }\end{array}$ & $\begin{array}{l}\text { cross-sectional study, } \\
\text { MISSCARE Survey }\end{array}$ & $\begin{array}{l}\mathrm{n}=4,412 \text { nursing staff } \\
\text { (nurses and NAs) }\end{array}$ & $\begin{array}{l}\text { The level of teamwork affects } \\
\text { the extent and nature of missed } \\
\text { care; adaptation of Missed } \\
\text { Nursing Care Model (Kalich et } \\
\text { al., 2009) inc. teamwork. }\end{array}$ \\
\hline & $\begin{array}{l}\text { Kalisch et al. } \\
(2011)\end{array}$ & $\begin{array}{l}\text { To determine the prevalence of and the } \\
\text { underlying reasons for missed care } \\
\text { across hospitals. }\end{array}$ & $\begin{array}{l}\text { cross-sectional study, } \\
\text { MISSCARE Survey }\end{array}$ & $\begin{array}{l}\mathrm{n}=4,086 \text { nursing staff } \\
(3,143 \text { nurses, } 943 \text { NAs) }\end{array}$ & $\begin{array}{l}\text { Adaptation of Missed Nursing } \\
\text { Care Model (Kalisch et al., } \\
\text { 2009). }\end{array}$ \\
\hline \multirow[t]{2}{*}{$\begin{array}{l}\text { Implicit rationing } \\
\text { of nursing care } \\
\text { approach }\end{array}$} & $\begin{array}{l}\text { Schubert et al. } \\
\text { (2007) }\end{array}$ & $\begin{array}{l}\text { To examine the psychometric } \\
\text { properties of the newly developed } \\
\text { instrument. }\end{array}$ & $\begin{array}{l}\text { instrument development } \\
\text { report }\end{array}$ & $\mathrm{n}=957$ nurses & $\begin{array}{l}\text { The Basel Extent Rationing of } \\
\text { Nursing Care (BERNCA) } \\
\text { instrument - valid and reliable } \\
\text { instrument; development of } \\
\text { conceptual framework regarding } \\
\text { implicit rationing of nursing } \\
\text { care. }\end{array}$ \\
\hline & $\begin{array}{l}\text { Schubert et al. } \\
\text { (2008) }\end{array}$ & $\begin{array}{l}\text { To investigate the connection between } \\
\text { implicit rationing of nursing care and } \\
\text { particular patient outcomes using the } \\
\text { BERNCA instrument. }\end{array}$ & $\begin{array}{l}\text { multi-hospital cross- } \\
\text { sectional surveys of } \\
\text { patients and nurses }\end{array}$ & $\begin{array}{l}\mathrm{n}=1,338 \text { nurses, } \\
\mathrm{n}=779 \text { patients }\end{array}$ & $\begin{array}{l}\text { Six patient outcomes were } \\
\text { related to the implicit rationing } \\
\text { of nursing care; the conceptual } \\
\text { framework was used as in } \\
\text { Schubert et al. (2007). }\end{array}$ \\
\hline
\end{tabular}


Table 1 Overview of studies related to the concept of missed/rationed/unfinished care phenomenon (Part 2)

\begin{tabular}{|c|c|c|c|c|c|}
\hline Primary focus & Source & Objective & Design & Sampling & Main findings \\
\hline & $\begin{array}{l}\text { Schubert et al. } \\
(2013)\end{array}$ & $\begin{array}{l}\text { To explore the prevalence of implicit } \\
\text { rationing of care and to determine the } \\
\text { connections between nine potential } \\
\text { rationing predictors and implicit } \\
\text { rationing of nursing care. }\end{array}$ & $\begin{array}{l}\text { cross sectional multi- } \\
\text { center study }\end{array}$ & $\mathrm{n}=1,633$ nurses & $\begin{array}{l}\text { Two of nine predictors were } \\
\text { confirmed by multilevel } \\
\text { regression analysis; adaptation } \\
\text { of the BERNCA instrument to } \\
\text { the BERNCA- R instrument. }\end{array}$ \\
\hline & $\begin{array}{l}\text { Rochefort, Clarke } \\
\text { (2010) }\end{array}$ & $\begin{array}{l}\text { To describe the association between } \\
\text { work environment characteristics and } \\
\text { neonatal intensive care unit nurses' } \\
\text { perceptions of rationing of care, job } \\
\text { outcomes, and quality of care; to } \\
\text { evaluate the psychometric properties of } \\
\text { the NEWRI instrument. }\end{array}$ & $\begin{array}{l}\text { cross-sectional study, } \\
\text { NEWRI instrument }\end{array}$ & $\mathrm{n}=339$ nurses & $\begin{array}{l}\text { The study revealed the } \\
\text { relationship between selected } \\
\text { variables; the NEW-RI appears } \\
\text { to be a valid and reliable tool for } \\
\text { monitoring the extent of } \\
\text { rationing of nursing care in } \\
\text { neonatal unit. }\end{array}$ \\
\hline & $\begin{array}{l}\text { Papastavrou, } \\
\text { Andreou, } \\
\text { Efstathiou } \\
(2014)\end{array}$ & $\begin{array}{l}\text { To determine experiences and } \\
\text { perceptions of nurses regarding } \\
\text { prioritization, omission and rationing } \\
\text { of nursing care provided bedside. }\end{array}$ & qualitative report & $\begin{array}{l}4 \text { focus groups } \\
\mathrm{n}=23 \text { nurses }\end{array}$ & $\begin{array}{l}\text { Work environment of nurses is } \\
\text { considered to have an influence } \\
\text { on prioritization of nursing care. } \\
\text { Rationing of nursing care can } \\
\text { lead to negative outcomes for } \\
\text { patients, and other adverse } \\
\text { events. }\end{array}$ \\
\hline & Jones & To assess the psychometric properties & cross-sectional study, & $\mathrm{n}=226$ nurses & The Perceived Implicit \\
\hline & $(2014)$ & $\begin{array}{l}\text { of the newly modified instrument - the } \\
\text { PIRNCA instrument. }\end{array}$ & validation study & including managers & $\begin{array}{l}\text { Rationing of Nursing Care } \\
\text { (PIRNCA) instrument }- \text { valid } \\
\text { and reliable instrument. }\end{array}$ \\
\hline & $\begin{array}{l}\text { Jones et al. } \\
(2014)\end{array}$ & $\begin{array}{l}\text { To clarify the concept of rationing } \\
\text { from an economic perspective. }\end{array}$ & an overview report & $\mathrm{NA}^{*}$ & $\begin{array}{l}\text { Clarification of the concept of } \\
\text { rationing care in nursing; } \\
\text { rationalisation of nursing care. }\end{array}$ \\
\hline & $\begin{array}{l}\text { Jones } \\
(2015)\end{array}$ & $\begin{array}{l}\text { To explore implicit rationing among } \\
\text { US nurses, and identify the frequency } \\
\text { and patterns of the phenomenon in the } \\
\text { US, as yet not explored. }\end{array}$ & cross-sectional study & $\begin{array}{l}\mathrm{n}=226 \text { nurses } \\
\text { including managers }\end{array}$ & $\begin{array}{l}\text { Description of the concept of } \\
\text { implicit rationing of nursing care } \\
\text { in the context of healthcare. }\end{array}$ \\
\hline
\end{tabular}


Table 1 Overview of studies related to the concept of missed/rationed/unfinished care phenomenon (Part 2)

\begin{tabular}{|c|c|c|c|c|c|}
\hline Primary focus & Source & Objective & Design & Sampling & Main findings \\
\hline \multirow[t]{2}{*}{$\begin{array}{l}\text { Task undone } \\
\text { approach }\end{array}$} & $\begin{array}{l}\text { Aiken et al. } \\
(2001)\end{array}$ & $\begin{array}{l}\text { To report the nurses' perceptions of } \\
\text { hospital care in five countries. }\end{array}$ & $\begin{array}{l}\text { cross-sectional study, } \\
\text { instrument TU-7 }\end{array}$ & $\begin{array}{l}\mathrm{n}=13,471 \text { nurses } \\
\text { (USA), } \mathrm{n}=17,450 \\
\text { nurses (Canada), } \\
\mathrm{n}=2,681 \\
\text { nurses (Germany), } \\
\mathrm{n}=5,006 \\
\text { nurses (England), } \\
\mathrm{n}=4,721 \\
\text { nurses (Scotland) } \\
\text { total } \mathrm{n}=43,329 \text { nurses }\end{array}$ & $\begin{array}{l}\text { Illustration of inadequate } \\
\text { hospital nurse staffing as } \\
\text { a global problem, contributing to } \\
\text { decline in quality-of-care, } \\
\text { medication errors, and negative } \\
\text { patient outcomes. }\end{array}$ \\
\hline & $\begin{array}{l}\text { Zhu et al. } \\
(2012)\end{array}$ & $\begin{array}{l}\text { To explore the association between } \\
\text { nursing staff and patient outcomes. }\end{array}$ & $\begin{array}{l}\text { cross-sectional study, } \\
\text { instrument TU-5 }\end{array}$ & $\mathrm{n}=7,802$ nurses & $\begin{array}{l}\text { Inadequate numbers of nursing } \\
\text { staff may lead to missed care and } \\
\text { negative patient outcomes; } \\
\text { adaptation of TU-7 instrument } \\
\text { (Aiken et al., 2001). }\end{array}$ \\
\hline \multirow[t]{2}{*}{$\begin{array}{l}\text { Failure to } \\
\text { Maintain }\end{array}$} & $\begin{array}{l}\text { Bail, Grealish, } \\
\text { (2016) }\end{array}$ & $\begin{array}{l}\text { To introduce the concept of Failure to } \\
\text { Maintain, and to provide a conceptual } \\
\text { framework of the phenomenon in } \\
\text { nursing care provided to older } \\
\text { hospitalized patients. }\end{array}$ & concept analysis report & $\mathrm{NA}^{*}$ & $\begin{array}{l}\text { Development of conceptual } \\
\text { framework of Failure to } \\
\text { Maintain in elderly patients in } \\
\text { hospitals. }\end{array}$ \\
\hline & $\begin{array}{l}\text { Sheetz et al. } \\
(2014)\end{array}$ & $\begin{array}{l}\text { To assess the association between } \\
\text { specific complications and Failure to } \\
\text { Rescue rates in elderly patients across } \\
\text { hospitals, stratified by mortality. }\end{array}$ & population-based study & $\mathrm{n}=23,217$ patients & $\begin{array}{l}\text { The study used the concept of } \\
\text { Failure to Rescue; after } \\
\text { complications (such as infectious } \\
\text { or pulmonary), elderly patients } \\
\text { have higher Failure to Maintain } \\
\text { rates than younger patients. }\end{array}$ \\
\hline
\end{tabular}


responses. In the missed nursing care model, the antecedents are occurrences that can lead to the determination of specific nursing activities that are performed (or not performed) and completed (Kalisch, Landstrom, Hinshaw, 2009). Additionally, the results are incidents or events that may be defined as outcomes; i.e., patient outcomes and results. For example, missed care might include the inadequate education of a patient with diabetes, which has the potential to lead to further complications or readmission (Kalisch, 2006).

The Missed Nursing Care Model has led to the development of the MISSCARE Survey (a measurement tool) which helps to identify the phenomenon (Kalisch, Williams, 2009). Based on existing literature, Kalisch and Lee (2010) modified the Missed Nursing Care Model by including the additional variable teamwork into the model, as teamwork among healthcare providers is seen as playing a key role in patient safety. The main concept and integrity of the Missed Nursing Care Model is maintained by the inclusion of the additional variable. In 2011, Kalisch et al. expanded their findings by presenting a conceptual framework exploring three concepts. The first concept relates to particular hospitals, care units or individual characteristics of nursing staff. The second regards missed care, and the third refers to staff outcomes (including job satisfaction), and patient outcomes (including pressure ulcer prevalence and incidences of falls). The following variables have been identified: a) structure variables, including patient units; individual nursing staff characteristics; and hospitals; and b) process variables, comprising missed care (Kalisch, Landstrom, Hinshaw, 2009; Kalisch, Lee, 2010; Kalisch et al., 2011). Numerous characteristics of nursing staff and the unit in which they work have been linked to patient outcomes and results.

Hessels et al. (2015) used the Missed Nursing Care Model developed by Kalisch, Landstrom, Hinshaw (2009) as the conceptual framework for their study. Hessels et al. (2015) created a model which speculates that the features of the organizational system significantly influence the decision-making of nursing staff. Additionally, they found that within the nursing process, particular tasks left undone lead to negative outcomes for patients. This suggests that when time constraints occur, nurses arrange and prioritize the aspects of care that are rendered or omitted. Decisions made in the context of the nursing environment are defined as the "organizational characteristics of a work setting that facilitate or constrain professional nursing practice" (Kalisch, Williams, 2009; Kalisch et al., 2011).

It is important to point out that hospital work environment settings also have organizational and professional practice characteristics. These include material resource allocation (availability of medications, supplies, and other operational equipment); labor resource allocation (number and type of nurses, competencies, educational level) and inter-professional relationships; teamwork; and communication (Kalisch, Landstrom, Hinshaw, 2009). The organizational support for the nursing practice environment include adaptable core characteristics, including supportive front-line managers, adequate resources, foundations for quality care, nurse participation in organizational decisionmaking, and collaborative relationships with physicians. These factors dramatically influence nursing prioritization in decision-making situations, so it is plausible to conclude that they have a direct impact on what nurses and nursing staff choose to do, or disregard, when it comes to patient care (Hessels et al., 2015). By inference, it would seem that missed nursing care is a direct reflection of the internal decision-making process of nurses who combine and integrate external antecedent factors such as the work environment and selected characteristics of a hospital and its internal setting and conditions.

\section{The implicit rationing approach}

The phrase "implicit rationing of nursing care" was coined by Schubert and her colleagues (2007) in the Rationing of Nursing Care in Switzerland (RICH Nursing Study), who measured the levels of care in Swiss acute care hospitals (Schubert et al., 2008).

The notion of rationing of care is often reported in healthcare worldwide in an economic context, with a strong focus on cost reductions (Papastavrou, Andreou, Efstathiou, 2014). The term "rationing" is expounded by Jones (2014), who describes the use of the word as the allocation of resources in the context of scarcity. It is used mainly within the healthcare profession in the context of supply and demand, and needs versus amount available. In the healthcare context, this translates into the rationing of care, and includes deliberate decisions to limit or withhold valuable services due to inadequate resources (i.e., funds, staff, and medical equipment). The concept is best viewed from an economic perspective (Jones et al., 2014). Healthcare decision-making is a multiplelevel, complex, and, often, non-transparent system in which saving and rationing of resources occur at the macro level (government or health authority), the meso level (health facilities, organizational factors including budget allocation), and the micro level 
(healthcare professionals). Macro- and meso-level decisions are normally formed by administrative authorities in the form of concrete policies and fixed spending and monetary plans. Decisions which fall under this category are either administrative or political, and can be considered a form of explicit rationing. Decisions taken at the micro level commonly focus on individual patients, and are based on the thinking and experience of nursing professionals. These decisions are also considered implicit rationing, as they are both discretionary and clinical (Jones, 2015). In fully comprehending the economic perspective, the notion of implicit rationing of nursing care can be applied. However, in the context of quality and patient safety, a more accurate label of this type of decision-making is missed nursing care.

A conceptual framework to explain implicit rationing of nursing care was developed by Schubert et al. (2007), and was based on available empirical data, including the impetus influencing the decisionmaking of nursing staff. The data also indicated nursing professionals' prioritizing tendencies, as well as the outcomes of these on both patients and nurses. Both influences and constructs of these decisions are emphasized. The conceptual framework indicates the use of implicit rationing in nursing care when individual healthcare workers lack sufficient resources to adequately care for their patients (Schubert et al., 2008; Schubert et al., 2013). The extent of rationing is measured by the number of necessary nursing activities omitted or withheld. Schubert et al. (2007) defined deliberate omission as "the withholding of or failure to carry out necessary nursing measures for patients due to a lack of nursing resources (staffing, skill mix, time)". This definition is essentially the same as Kalisch outlines in his micro-level analysis (Schubert et al., 2013). Health rationing is influenced by both an organization's capabilities and the individual nurses' judgment and clinical decision-making (Schubert et al., 2008). Available nursing resources (i.e., skills, expertise of the staff) additionally influence healthcare workers' ability to meet patients' needs. Selected characteristics of nurses (i.e., educational level, experience) and patients (i.e., type of disease, severity, co-morbidities) contribute to the prevalence of health rationing. The characteristics of hospitals (including budgets, number of beds), the work environment of nurses, and the philosophy of care (standards of nursing care applied, cultural values) influence the nursing process of care and, by association, the rationing of that care (Schubert et al., 2007). Schubert et al. (2008) indicate that care rationing points to a significant and potentially powerful quality care indicator.

In a further study, Schubert et al. (2013) suggest that nurses prioritize and designate their care functions, especially those functions related to the areas of caring and support. This framework also uncovers the relationship between rationing, characteristics of patients and nurses and their outcomes, and organizational factors in the system. As illustrated previously under the conceptual framework, the phenomenon of health rationing occurs precisely at the point of patient-to-nurse interaction. It is also the result of critical judgment, as well as clinical decision-making. The process of decision-making entails several steps, including information collection, problem identification, alternative strategy planning, and optimal action selection, and is significantly influenced by education level, hospital culture and environment, leadership, and the condition of patients, as well as the responsibility, willingness, and confidence of the nurse (Schubert et al., 2007; Jones, 2015). The notion of prioritization in clinical nursing practice is directly influenced by selected characteristics of work atmosphere and environment; resources (time, material allocation, healthcare staff); the care philosophy provided; and organizational objectives (safety culture, nursing care standards, regulations, hospital guidelines); as well as patient characteristics and the acuteness of their condition (seriousness and number of problems); and the medical treatment plan and characteristics of nurses (education, experience). Schubert et al. (2013) suggests that all factors have implicit influence on the rationing of nursing care. However, the factors considered most relevant are the number of nursing staff, and the balance between nursing resources and the care needs of patients.

Several instruments have been developed to measure the phenomenon of health rationing. Schubert et al. (2007) developed the Basel Extent Rationing of Nursing Care (BERNCA) instrument for nurses in Switzerland. Jones (2014) modified a version of Schubert's instrument and published The Perceived Implicit Rationing of Nursing Care (PIRNCA) instrument, which was originally developed for American medical-surgical nurses. A third instrument measuring the rationing of care was developed by Rochefort and Clarke (2010), and is known as the Neonatal Extent of Work Rationing instrument (NEW-RI).

\section{The task undone approach}

The task undone approach has emerged from the International Hospital Outcomes Research Consortium (IHORC), which was formed by the 
University of Pennsylvania School of Nursing's Center for Health Outcomes and Policy Research (Sochalski, 2004). This approach was cited in many studies (Aiken et al., 2001; Al-Kandari, Thomas, 2009; Lucero, Lake, Aiken, 2009; Sermeus et al., 2011; Zhu et al., 2012) using the specific term "task undone" (TU). There are several versions of the instrument (TU-5, TU-7, TU-9, TU-13). The conceptual framework for the task undone approach was not described until Lucero, Lake, Aiken (2009) conducted their study, using the Process of Care and Outcomes Model (PCOM), derived from Donabedians' (1966) quality paradigm, and is also in the Quality Health Outcomes Model (QHOM) published by Mitchell et al. (1998). The PCOM model regards quality-of-care in terms of necessary things left undone by nursing staff (Lucero, Lake, Aiken, 2009). Lucero, Lake, Aiken (2009) also defined tasks left undone as activities which nurses did for patients. The PCOM shows a relationship between patient characteristics, the caring process, outcomes, and the environment in which the care is provided. According to Lucero, Lake, Aiken (2009), patient factors, the process of care, and the care environment have a direct impact on outcomes. The model also indicates that the effect of particular interventions are mediated by the system and patient factors. On the other hand, it is thought to have no direct independent effect. Nursing care is also considered to have a surveillance function in a healthcare organization, used for the early detection of changes in patients' health conditions. Following the adaptation of nurses to the changes in the environment of care and patients' health condition, the association between the process of care and outcomes can be influenced by variables. The work environment of nurses, nursing staff, and the size and ownership of the hospital are structural variables that influence the process of care, patients, and outcomes. The unmet nursing care needs, or tasks undone, or unfinished nursing activities are frequently reported by RN's, and, at the same time, various authors use these activities as a hospital-level nursing care quality indicator (Lucero, Lake, Aiken, 2009; Jones, Hamilton, Murry, 2015). The tasks undone are then reflected in the quality of nursing care provided and the overall process of care with negative patient outcomes.

\section{Failure to Maintain - theoretical proposition}

A number of studies were identified focusing on elderly patients, who have higher rates of complications acquired in hospital. These complications contribute to negative patient outcomes. This was also explored in the context of dramatically increased length of stays and costs for hospitals. In this context, the newest conceptual framework was published by Bail and Grealish (2016). They identified four critical complications of hospitalized elderly patients with cognitive impairment, focusing on patients with dementia. The rationale for the framework is the prioritization of care due to the excessive demands for nursing care. They found that basic nursing activities are implicitly rationed. These were: communication, the mobility of the patient, skin care, nutrition, and hydration leading to complications which are potentially preventable. Nonetheless, the care required to prevent these complications seems to be rationed by nurses.

Not only do older hospitalized patients have complex needs (e.g., those with dementia), but they are also more sensitive to the experience of rationing of care, as their care tends to take longer and is less curative and predictable. This theoretical framework suggests that the rationing of care contributes mostly to functional and cognitive decline during hospitalization of older patients. Furthermore, the authors of this framework indicate that these four complications are also indicators of a "Failure to Maintain" complex in older patients in hospitals. To deepen knowledge of the conceptual framework, the focus emphasizes two different concepts, i.e., Implicit Rationing of Nursing Care and Failure to Rescue, as measures of quality. The first is well described in the implicit rationing literature, and it deals with the same issues. The second refers to death following hospital-acquired complications. It is a wellrecognized term, but it is also important to emphasize that "Failure to Rescue" excludes patients aged over 75.

Patients over 75 have higher rates of "Failure to Rescue", mostly after pulmonary infectious complications (Sheetz et al., 2014). Bail and Grealish (2016) believe that the accompanying concept of Failure to Rescue could be useful for elderly patients in monitoring and evaluating hospital care for elderly patients. The conceptual framework also includes selected characteristics of the work environment of nurses, such as nursing staff and skill mix, relationships with managers and physicians, organization and support of the institution, and gerontologized hospital culture. Additional components are the complex characteristics of elderly patients, and indicators of "Failure to Maintain", which represent the four main complications. The most rationed nursing activities are illustrated in the framework. The framework shows that implicit rationing of nursing care leads directly to hospitalacquired complications. According to Bail and Grealish (2016), interactions between nurses, clinical 
practice and the socio-political contexts of contemporary hospitals are visible. This theoretical framework is complex but narrow, focusing on specific groups of patients and the nurses who provided care to them.

\section{Discussion}

The study aimed to describe, analyze and compare four approaches to understanding the phenomenon of missed/rationed/unfinished nursing care. The approach of missed care was first identified by Kalich (2006), and refers to nursing care which is regularly missed or omitted (Palese et al., 2015). According to Kalich and Lee (2010), missed care is an error of omission, as opposed to an error of commission. The conceptual framework published by Kalisch, Landstrom, Hinshaw (2009) was later modified by Kalisch and Lee (2010) to include level of nursing teamwork as one of the variables predicting missed care. Kalisch (2006) determined that missed care is the result of decision-making in terms of quality and patient safety. The main differences in identified conceptual frameworks lie in the understanding of the decision-making process in the rationalization of nursing care (Jones et al., 2014). Similarly to Kalisch, Schubert et al. (2007) identified implicit rationing of nursing care, and provided a list of nursing activities withheld due to lack of nursing resources. Jones et al. (2014) determined implicit rationing of care as a process of decision-making. Both conceptual frameworks suggest that multiple factors influence decision-making by nursing staff, and that this often results in the prioritization of nursing activities (Papastavrou, Andreou, Efstathiou, 2014; Schubert et al., 2013). While nurses need to prioritize their activities, this can lead to implicit rationing of care, unfinished care, or missed care (Jones, Hamilton, Murry, 2015).

Several authors (Jones et al., 2014; Jones, 2014; Hessels et al., 2015) connect implicit rationing of care with an unhealthy work environment for nurses, and understand the phenomena as an economic problem in healthcare systems around the world. The basis for the task undone approach is accompanied by the quality-of-care paradigm. The main variables are the caring process and quality of this process in the context of tasks left undone. Lucero, Lake, Aiken (2009; 2010), and Sochalski (2004) examined the association between quality of care and tasks left undone, including variables such as the care environment, patient characteristics, or outcomes of patients and organizations. The lastest conceptual framework, published by Bail and Grealish (2016), focuses on a specific group of elderly patients with dementia or other cognitive impairments. The authors examined the rationing of care with two different concepts - "Failure to Rescue" and "Failure to Maintain". "Failure to Rescue" is a well-recognized term, and it has become prevalent in monitoring and evaluating health services (Kane et al., 2007; Twigg et al., 2011; Aiken et al., 2013; Neff et al., 2013; Sheetz et al., 2014). The second term includes the rationing of care. In this case, the term has the same meaning as in the implicit rationing of care approach. This conceptual framework also includes previously mentioned characteristics, but also newly identified key indicators of the concept "Failure to Maintain", and specific activities which are rationed by nurses; as well as patients' experiences of functional and/or cognitive decline (Bail, Grealish, 2016). In general, the concepts of missed/rationed/unfinished nursing care are similar in the context of organizational system structure. No differences were identified. In addition, selected aspects of the working environment of nurses and workforce of nurses were represented as antecedents of the phenomenon in all models.

The selected characteristics of patients were reported in only two conceptual frameworks - the task undone and the implicit rationing of nursing care (El-Jardali, Lagacé, 2005; Schubert et al., 2007; Ausserhofer et al., 2014). The adequacy of nursing staff was associated with missed care by Kalisch et al. (2011). Increased numbers of nursing staff has been linked to a reduction in some patient outcomes, e.g., mortality (Needleman et al., 2002; Aiken et al., 2003), occurrence of nosocomial infections (Cimiotti et al., 2006; Hugonnet, Chevrolet, Pittet, 2007), pressure ulcers (Unruh, 2003) and falls (Dunton et al., 2004). When patient load and nursing staff absenteeism rates are high, patient mortality is reportedly higher too (Unruh, Joseph, Strickland, 2007). Studies also identified a connection between work schedules and patient outcomes, and suggested a direct and negative impact due to slower response time, decreased decision-making by nursing staff, impaired judgment, or increased risk of errors (Scott et al., 2006). Hessels et al. (2015) suggest that missed care is the result of the impact of nursing practice environment. Issues of patient safety culture were reported in all models, as well as nursing outcomes (Schubert et al., 2007; Kalisch et al., 2011; Ausserhofer et al., 2014; Bail, Grealish, 2016), on the other hand the organizational outcomes were represented only in the task undone approach (Lucero, Lake, Aiken, 2009).

\section{Limitations of study}

Only studies published in English from specific scientific databases that were open access and available electronically were accessed for this 
literature review. Only studies published in the time period between 2000 and 2018 were involved in the analysis, due to the increase in literature in this period. No critical appraisal tool was used to assess the quality of the studies. Researchers relied on their own judgment.

\section{Conclusion}

This literature review of conceptual frameworks provides a better understanding of the phenomenon of missed/rationed/unfinished nursing care. It suggests that the phenomenon is mostly a problem of lack of time, which precipitates the process of implicit rationing of nursing care due to the need to prioritise. Such an environment among nurses results in nursing activities being left undone. At the same time, evidence represents a bridge linking nursing staff to patient outcomes. Findings from studies also suggest that the phenomenon of missed care is routinely practiced by hospital nurses around the world, and occurs across all categories of nursing care (e.g., documentation of care, emotional care, and support, physical care or coordination of care). The phenomenon is associated with adverse patient and nursing outcomes, and it is a strong predictor of patient outcomes, as well as a quality-of-care indicator. The most prominent difference between the four frameworks is the component of missed/rationed/unfinished care, which is best described as a difference in terminology rather than substance. There is no consensus in terminology, and different terms are used regarding particular frameworks. Missed/rationed/unfinished nursing care is an issue we should be concerned about, as it remains a phenomenon that is not well understood. This may have a negative impact on systematic research in this area, and may negatively influence patient outcomes, in the ways we have described. There is still a lack of knowledge about the whole process, which leads to its continued occurrence in clinical nursing practice, and we therefore recommend it be further explored.

\section{Ethical aspects and conflict of interest}

All literature resources were cited.

The article was supported by COST OC -2015-220085 Rationing Missed Nursing Care: An international and multidimensional problem.

\section{Author contributions}

Conception and design (DK, KŽ), data analysis and interpretation (DK, RK), manuscript draft (DK, KŽ), critical revision of the manuscript (DK, KŽ, RK), final approval of the manuscript (DK).

\section{References}

Aiken LH, Clarke SP, Sloane DM, Sochalski JA, Busse R, Clarke H, Giovannetti P, Hunt J, Rafferty AM, Shamian J. Nurses' reports on hospital care in five countries. Health Affairs. 2001;20(3):43-53.

Aiken LH, Clarke SP, Cheung RB, Sloane DM, Silber JH. Educational levels of hospital nurses and surgical patient mortality. JAMA: The Journal of the American Medical Association. 2003;290(12):1617-1623.

Aiken, LH, Sloane DM, Bruyneel L, Van den Heede K, Sermeus W; RN4CAST Consortium. Nurses' reports of working conditions and hospital quality of care in 12 countries in Europe. International Journal of Nursing Studies. 2013;50(2):143-153.

Al-Kandari F, Thomas D. Factors contributing to nursing task incompletion as perceived by nurses working in Kuwait general hospitals. Journal of Clinical Nursing. 2009;18(24):3430-3440.

Ausserhofer D, Zander B, Busse R, Schubert M, DeGeest S, Rafferty AM, Ball J, Scott A, Kinnunen J, Heinen M, Sjetne IS, Moreno-Casbas T, Kózka M, Lindqvist R, Diomidous M, Bruyneel L, Sermeus W, Aiken LH, Schwendimann R; RN4CAST consortium. Prevalence, patterns and predictors of nursing care left undone in European hospitals: results from the multicountry cross-sectional RN4CAST study. BMJ Quality \& Safety. 2014;23(2):126-135.

Bail K, Grealish L. "Failure to Maintain": a theoretical proposition for a new quality indicator of nurse care rationing for complex older people in hospital. International Journal of Nursing Studies. 2016;63:146-161.

Ball JE, Murrells T, Rafferty AM, Morrow E, Griffiths P. "Care left undone" during nursing shifts: associations with workload and perceived quality of care. BMJ Quality \& Safety. 2014;23(2):116-125.

Bassi E, Tartaglini D, Palese A. Missed nursing care terminologies, theoretical concepts and measurement instruments: a literature review. Assistenza Infermieristica $e$ Ricerca. 2018;37(1):12-24.

Bekker M, Coetzee SK, Klopper HC, Ellis SM. Non-nursing tasks, nursing tasks left undone and job satisfaction among professional nurses in South African hospitals. Journal of Nursing Management. 2015;23(8):1115-1125.

Cimiotti JP, Haas J, Saiman L, Larson EL. Impact of staffing on bloodstream infections in the neonatal intensive care unit. Archives of Pediatrics and Adolescent Medicine. 2006;160(8):832-836.

Donabedian A. Evaluation quality of medical care. The Milbank Quarterly. 1966;44(3):166-206.

Dunton N, Gajewski B, Taunton RL, Moore J. Nurse staffing and patient falls on acute care hospital units. Nursing Outlook. 2004;52(1):53-59.

El-Jardali F, Lagacé M. Making hospital care safer and better: the structure-process connection leading to adverse events. Healthcare Quarterly. 2005;8(2):40-48.

Hessels AJ, Flynn L, Cimiotti JP, Cadmus E, Gershon RRM. The impact of the nursing practice environment on missed nursing care. Clinical Nursing Studies. 2015;3(4):60-65.

Hugonnet S, Chevrolet JC, Pittet D. The effect of workload on infection risk in critically ill patients. Critical Care Medicine. 2007;35(1):76-81. 
Jones TL. Validation of the Perceived Implicit Rationing of Nursing Care (PIRNCA) instrument. Nursing Forum. 2014;49(2):77-87.

Jones T, Hamilton P, Carryer J, Sportsman S, Gemeinhardt G. International network for the study of rationalised nursing care - an overview. 2nd Annual Worldwide Nursing Conference, 2014 [cited 2018 May 14]. Available from: http://dl4.globalstf.org/?wpsc-product=international-networkfor-the-study-of-rationalised-nursing-care-an-overview Jones TL, Hamilton P, Murry N. Unfinished nursing care, missed care, and implicitly rationed care: State of the science review. International Journal of Nursing Studies. 2015;52(6):1121-1137.

Jones TL. A descriptive analysis of implicit rationing of nursing care: frequency and patterns in Texas. Nursing Economics. 2015;33(3):144-154.

Jones TL, Gemenihardt G, Thompson JA, Hamilton P. Measuring unfinished nursing care: what to consider when choosing and scoring surveys. Journal of Nursing Care Quality. 2016;31(1):90-97.

Kalisch BJ. Missed nursing care: a qualitative study. Journal of Nursing Care Quality. 2006;21(4):306-313.

Kalisch BJ, Landstrom GL, Hinshaw AS. Missed nursing care: a concept analysis. Journal of Advanced Nursing. 2009;65(7):1509-1517.

Kalisch BJ, Williams RA. Development and psychometric testing of a tool to measure missed nursing care. Journal of Nursing Administration. 2009;39(5):211-219.

Kalisch BJ, Lee KH. The impact of teamwork on missed nursing care. Nursing Outlook. 2010;58(5):233-241.

Kalisch BJ, Tschannen D, Lee H, Friese CR. Hospital variation in missed nursing care. American Journal of Medical Quality. 2011;26(4):291-299.

Kane RL, Shamliyan TA, Mueller C, Duval S, Wilt TJ. The association of registered nurse staffing levels and patient outcomes: Systematic review and meta-analysis. Medical Care. 2007;45(12):1195-1204.

Lake ET, Germack HD, Viscardi MK. Missed nursing care is linked to patient satisfaction: a cross-sectional study of US hospitals. BMJ Quality \& Safety. 2016;25(7):535-543.

Leary A, White J, Yarnell L. The work left undone. Understanding the challenge of providing holistic lung cancer nursing care in the UK. European Journal of Oncology Nursing. 2014;18(1):23-28.

Lucero RJ, Lake ET, Aiken LH. Variations in nursing care quality across hospitals. Journal of Advanced Nursing. 2009;65(11):2299-2310.

Lucero RJ, Lake ET, Aiken LH. Nursing care quality and adverse events in US hospitals. Journal of Clinical Nursing. 2010;19(15-16):2185-2195.

Mitchell PH, Ferketich S, Jennings BM. Quality health outcomes model. American Academy of Nursing Expert Panel on Quality Health Care. Image - The Journal of Nursing Scholarship.1998;30(1):43-46.

Needleman J, Buerhaus P, Mattke S, Stewart M, Zelevinsky K. Nurse-staffing levels and the quality of care in hospitals. The New England Journal of Medicine. 2002;346(22):17151722.

Neff DF, Cimiotti J, Sloane DM, Aiken LH. Utilization of non-US educated nurses in US hospitals: implications for hospital mortality. International Journal for Quality in Health Care. 2013;25(4):366-372.

Palese A, Ambrosi E, Prosperi L, Guarnier A, Barelli P, Zambiasi P, Allegrini E, Bazoli L, Casson P, Marin M,
Padovan M, Picogna M, Taddia P, Salmaso D, Chiari P, Marognolli O, Canzan F, Gonella S, Saiani L. Missed nursing care and predicting factors in the Italian medical care setting. Internal and Emergency Medicine. 2015;10(6):693702.

Papastavrou E, Andreou P, Efstathiou G. Rationing of nursing care and nurse-patient outcomes: a systematic review of quantitative studies. The International Journal of Health Planning and Management. 2014;29(1):3-25.

Rochefort CM, Clarke SP. Nurses' work environments, care rationing, job outcomes, and quality of care on neonatal units. Journal of Advanced Nursing. 2010;66(10):2213-2224.

Schubert M, Glass TR, Clarke SP, Schaffert-Witvliet B, De Geest S. Validation of the Basel Extent of Rationing of Nursing Care instrument. Nursing Research. 2007;56(6):416424.

Schubert M, Glass TR, Clarke SP, Aiken LH, SchaffertWitvliet B, Sloane DM, De Geest, S. Rationing of nursing care and its relationship to patient outcomes: the Swiss extension of the International Hospital Outcomes Study. International Journal for Quality in Health Care. 2008;20(4):227-237.

Schubert M, Ausserhofer D, Desmedt M, Schwendimann R, Lesaffre E, Li B, De Geest S. Levels and correlates of implicit rationing of nursing care in Swiss acute care hospitals - a cross sectional study. International Journal of Nursing Studies. 2013;50(2):230-239.

Scott LD, Rogers AE, Hwang WT, Zhang Y. Effects of critical care nurses' work hours on vigilance and patients' safety. American Journal of Critical Care . 2006;15(1):30-37. Sermeus W, Aiken LH, Van den Heede K, Rafferty AM, Griffiths P, Moreno-Casbas MT, Busse R, Lindqvist R, Scott AP, Bruyneel L, Brzostek T, Kinnunen J, Schubert M, Schoonhoven L, Zikos D; RN4CAST consortium. Nurse forecasting in Europe (RN4CAST): Rationale, design and methodology. BMC Nursing. 2011;10:6.

Sheetz KH, Krell RW, Englesbe MJ, Birkmeyer JD, Campbell DA Jr, Ghaferi AA. The importance of the first complication: understanding failure to rescue after emergent surgery in the elderly. Journal of the American College of Surgeons. 2014;219(3):365-370.

Sochalski J. Is more better? The relationship between nurse staffing and the quality of nursing care in hospitals. Medical Care. 2004;42(2 Suppl):II67-II73.

Twigg D, Duffield C, Bremner A, Rapley P, Finn J. The impact of the nursing hours per patient day (NHPPD) staffing method on patient outcomes: a retrospective analysis of patient and staffing data. International Journal of Nursing Studies. 2011;48(5):540-548.

Unruh L. Licensed nurse staffing and adverse events in hospitals. Medical Care. 2003;41(1):142-152.

Unruh L, Joseph L, Strickland M. Nurse absenteeism and workload: negative effect on restraint use, incident reports and mortality. Journal of Advanced Nursing. 2007;60(6):673681.

Zeleníková R, Sermeus W, Papastavrou E, Gurková E, Efstathiou G. Research protocol: Cross-cultural understanding of the concept of rationed/missed/unfinished nursing care. 2017. Unpublished manuscript.

Zhu XW, You LM, Zheng J, Liu K, Fang JB, Hou SX, Lu MM, Lv AL, Ma WG, Wang HH, Wu ZJ, Zhang LF. Nurse staffing levels make a difference on patient outcomes: A multisite study in Chinese hospitals. Journal of Nursing Scholarship. 2012;44(3):266-273. 